\title{
A Decision Aid Intervention for Family Building After Cancer: Developmental Study on the Initial Steps to Consider When Designing a Web-Based Prototype
}

Catherine Benedict ${ }^{1,2}, \mathrm{PhD}$; Katherine L Dauber-Decker ${ }^{3}, \mathrm{PhD}$; D'Arcy King ${ }^{3}$, PhD; Alexandria Hahn ${ }^{4}$, MSc; Jennifer $\mathrm{S}_{\text {Ford }}{ }^{5}, \mathrm{PhD} ;$ Michael Diefenbach ${ }^{3}, \mathrm{PhD}$

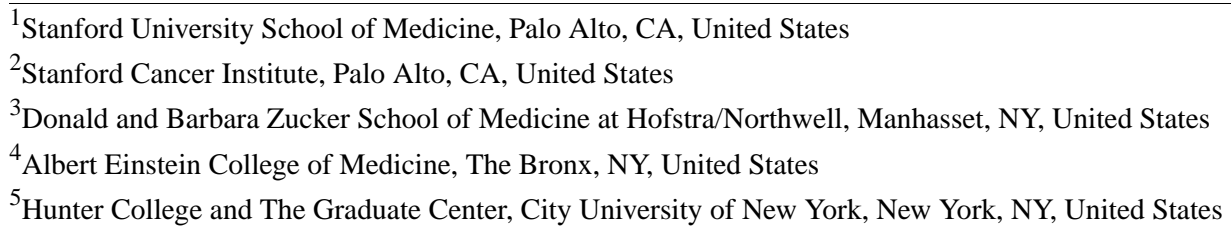

Corresponding Author:

Catherine Benedict, PhD

Stanford University School of Medicine

401 Quarry Road

Palo Alto, CA, 94305-5718

United States

Phone: 12012077117

Email: cbenedict@stanford.edu

\begin{abstract}
Background: An important aspect of patient-centered care involves ensuring that patient-directed resources are usable, understandable, and responsive to patients' needs. A user-centered design refers to an empathy-based framework and an iterative design approach for developing a product or solution that is based on an in-depth understanding of users' needs, values, abilities, and limitations.

Objective: This study presents the steps taken to develop a prototype for a patient resource for young women who have completed treatment for gonadotoxic cancer to support their decision making about follow-up fertility care and family building.

Methods: User-centered design practices were used to develop Roadmap to Parenthood, a decision aid (DA) website for family building after cancer. A multidisciplinary steering group was assembled and input was provided. Guidelines from the International Patient DA Society and the Ottawa Decision Support Framework were used throughout the development process. In addition, guidelines for developing health DAs with respect to patient diversity and health literacy were also followed.

Results: The Roadmap to Parenthood DA website prototype was systematically and iteratively developed. An extensive process of designing and developing solutions from the perspective of the end user was followed. The steps taken included formative work to identify user needs; determining goals, format, and delivery; design processes (eg, personas, storyboards, information architecture, user journey mapping, and wireframing); and content development. Additional design considerations addressed the unique needs of this patient population, including the emotional experiences related to this topic and decision-making context wherein decisions could be considered iteratively while involving a multistep process.

Conclusions: The design strategies presented in this study describe important steps in the early phases of developing a user-centered resource, which will enhance the starting point for usability testing and further design modifications. Future research will pilot test the DA and a planning tool, and evaluate improvement in the decisional conflict regarding family building after cancer. Consistent with a patient-centered approach to health care, the strategies described here may be generalized and applied to the development of other patient resources and clinical contexts to optimize usability, empathy, and user engagement.
\end{abstract}

(JMIR Form Res 2021;5(1):e20841) doi: $\underline{10.2196 / 20841}$

\section{KEYWORDS}

patient-centered care; user-centered design; decision support techniques; decision aid; cancer; fertility; internet-based intervention; web-based intervention; mobile phone; psychosocial intervention 


\section{Introduction}

\section{Background}

Patient-centered care is well established as an important aspect of health care quality. As put forth by the Institute of Medicine, all care should respect and be responsive to patients' preferences, needs, and values [1]. Patients should have access to education and support to act as informed decision makers and participate in shared decision making with providers to ensure that their individual values are reflected in the treatment plans [2]. Operationally, an important aspect of patient-centered care involves ensuring that patient-directed information, education, and communication are usable, understandable, and responsive to patients' needs. To support value-based decision making, it is important to develop patient resources with the target user group in mind.

This study focuses on oncofertility as an example of a clinical context in which there is an unmet need for patient-centered support. For young adult survivors of cancer (ie, aged 18-39 years), fertility is ranked among the most important survivorship issues [3,4]. Patient-centered resources are needed to inform patients about infertility risks and family-building options, support their decision making, guide their involvement in seeking care, and prepare them for potential future challenges. This paper describes the first phase of the development process of a patient decision aid (DA) and planning tool for family building after cancer.

\section{Family Building After Cancer}

Owing to gonadotoxic treatments, many women experience reduced ovarian function or are unable to safely carry a pregnancy to term after cancer. The prevalence of primary ovarian insufficiency in female survivors of pediatric, adolescent, and young adult cancers ranges from $2 \%$ to $82 \%$, based on patient factors, cancer diagnosis, and treatment exposures [5]. Alternative family-building options include the use of assisted reproductive technology, such as in vitro fertilization (IVF) and surrogacy, or adoption or fostering. With assisted reproduction, options comprise the use of fresh, frozen, or donated gametes to achieve pregnancy in the survivor or a gestational carrier. Adoption may be domestic or international. Each of these family-building options comes with a number of physical, emotional, financial, legal, and logistical challenges that need proper consideration; hence, decision making can be complex. For many patients, there may be benefits of an early action even if desired family building may be years away, including undergoing a fertility evaluation posttreatment to better understand their reproductive options and expected reproductive timeline, undergoing egg/embryo freezing posttreatment if they are at a risk for early menopause but not yet ready to start their family, or financial planning. Family-building decisions are based on values, and survivors must weigh the pros and cons of their options regarding risk-benefit tradeoffs. Given the emotional salience of motherhood desires, many women report high levels of uncertainty and distress when prompted to consider fertility and family-building decisions after cancer [6].

\section{Decision Support}

Young female survivors of cancer report unmet support needs related to posttreatment fertility care in survivorship and want to be provided informational resources to help them understand their options for pursuing future parenthood [7,8]. Patient DAs are effective for improving tailored decision-making quality such that the users are more likely to be informed, gain clarity about how their values align with their decision options, and take a more active role in decision making [9]. Advantages of delivering patient DAs over the internet include an increasing reach and potential effectiveness [10]. Multiple patient DAs exist for young women diagnosed with cancer who are considering fertility preservation before treatment $[11,12]$. Although these studies support the use of DAs for fertility-related decisions in the context of cancer care [11,12], to our knowledge, there are no decision support resources that address the posttreatment reproductive survivorship care and family-building decisions that must be made after the completion of treatment.

\section{User-Centered Design}

This study used user-centered design principles to develop a patient resource that supports decision making about family building after cancer treatment. A user-centered design is an empathy-based framework and an iterative design approach for developing a product or solution based on an in-depth understanding of users' needs, values, abilities, and limitations. This iterative process is effective and essential because it places end users at the center of every stage of development-in this case young adult female survivors of cancer-to ensure that the end product reflects and addresses their needs [13]. Conversely, the failure to consider end users' insights, feedback, and needs results in products and solutions that are less likely to achieve optimal adoption, retention, and advocacy [14]. Technology acceptance models and theories on telemedicine adoption highlight the importance of co-design with end users to develop products that are perceived as useful, easy to use, and responsive to needs $[15,16]$.

\section{Study Objectives}

To address a critical gap in young adult cancer survivorship care, we set out to develop a web-based patient DA and planning tool to support young women interested in family building after cancer. This study presents the steps taken to develop the prototype of the website, Roadmap to Parenthood, based on user-centered design practices and guidelines for developing DAs and health care resources for diverse patient groups and health literacy levels. This work was guided by a theoretical approach grounded in the self-regulation theory $[17,18]$ and further developed in our preliminary work, which is described elsewhere $[19,20]$. In this paper, we review the initial design steps and process to develop a DA prototype before conducting formal usability testing. These steps aim to optimize usability, empathy, and user engagement to ensure universal applicability across patient subgroups. Our intention in this paper is to thoroughly describe the prototype design process, which allows us to enter a formal usability testing phase that considers key design issues and user feedback. 


\section{Methods}

\section{Preliminary Studies}

The study team led several oncofertility studies focusing on young adult female cancer survivors' experiences related to fertility and family building posttreatment and identified unmet decision-making needs and patient preferences for support. Our national survey of posttreatment reproductive concerns and decision making uncertainty identified the areas of decisional conflict about family building after cancer (eg, lack of information, clarification of values, and lack of emotional support) [6]. Two additional qualitative studies explored posttreatment fertility concerns [21] and family-building experiences [22] and informed our understanding of user needs. On the basis of this work, semistructured interviews $(\mathrm{N}=25)$ were conducted with young adult female survivors of cancer (aged 15-45 years) who received gonadotoxic treatment and were either interested in future family building or uncertain about their family-building plans [19]. Briefly, women reported high rates of unmet information needs, including uncertainty about reproductive survivorship care and where to obtain trusted information. They felt overwhelmed and distressed by the prospect of pursuing family building and its expected, associated challenges [19]. When asked about support preferences, they indicated a desire for step-by-step instructions to learn about their options and guide decision making and follow-up care [20]. They also reported a preference for web-based resources for self-education, which they envisioned would prepare them for and provide complementary support to in-person counseling with a clinician [20]. Notably, although the definition of young adult per the National Cancer Institute (NCI) is defined as an individual aged between 18 and 39 years, our work included women aged 15 to 45 years, as fertility and family-building concerns are highly relevant at somewhat younger and older ages $[23,24]$.

\section{Study Design}

The Roadmap to Parenthood DA and planning tool (website) was developed by following the steps depicted in Figure 1. The website was designed and tailored considering the shared experiences, emotions, and support needs of young adult female survivors of cancer identified in our previous work. All procedures followed user-centered design methods such that users' needs, contexts, and points of view were key drivers in the iterative design decisions throughout product development [15]. For this stage of the development process, decisions were made with input from patient research partners representing the target user population with the goal of optimizing the prototype design to best prepare for usability testing (which is currently underway). The development process followed the guidelines set forth by Coulter et al [25] and was consistent with the International Patient Decision Aid Society (IPDAS) and the Ottawa Decision Support Framework guidelines for patient DAs [25-28]. For the purposes of building a website, guidelines from the Department of Health and Human Services were followed for best practices of a user-centered web design and digital communication [29]. 
Figure 1. Steps taken to develop a patient decision aid and planning tool prototype using user-centered design strategies. Adapted from the user-centered design process map from the National Institutes of Health.
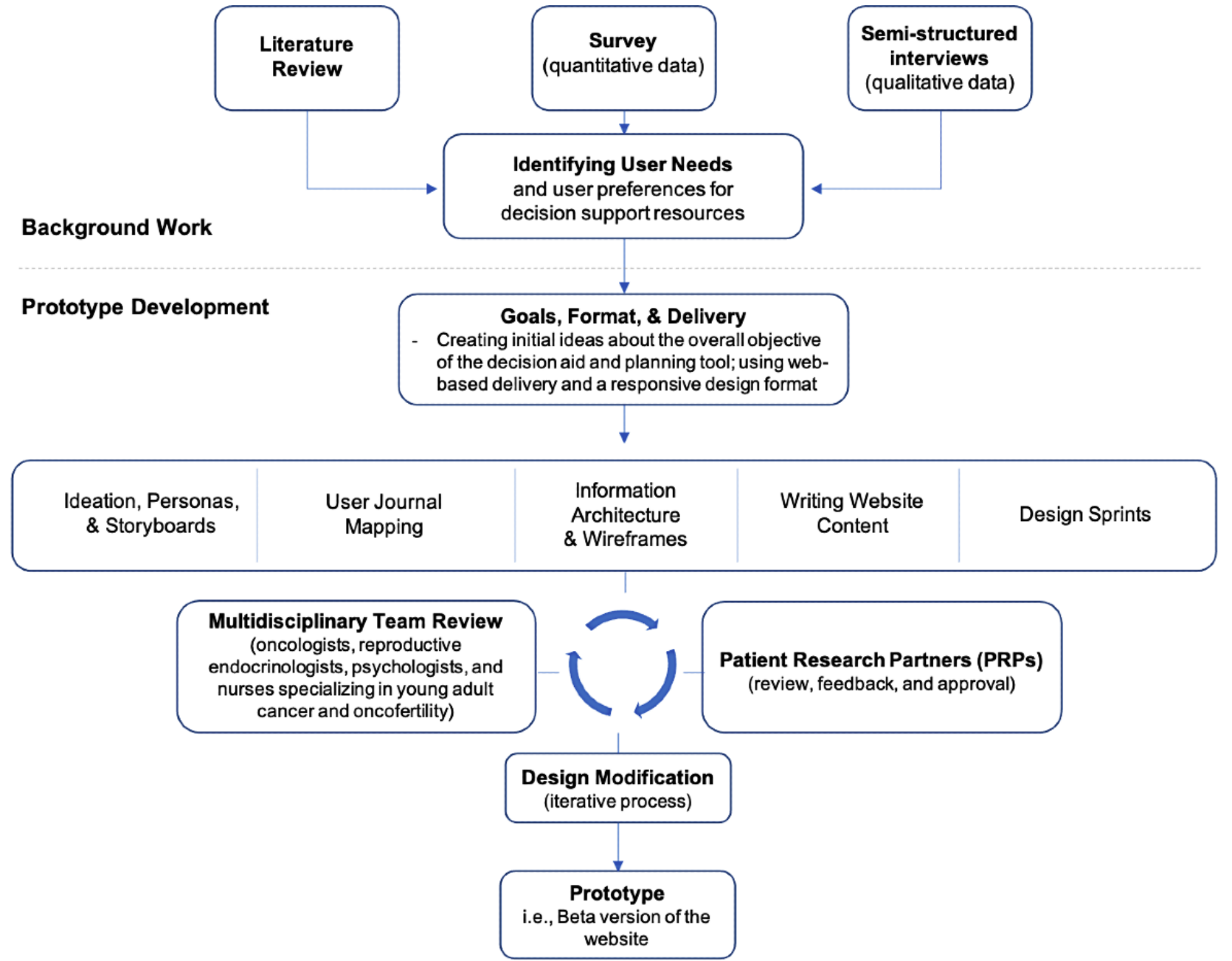

\section{Exploratory Work}

The research team reviewed and discussed oncofertility patient DAs, web-based oncofertility open access resources, and websites targeting young women such as those focused on women's health and fertility to explore ideas about structure, tonality, and appealing visual identity and design aesthetic for this demographic (Multimedia Appendix 1). The research team then completed a discovery worksheet to ensure alignment with the web developer regarding the goals of the project (Multimedia Appendix 2).

\section{Responsive Design Format}

We selected a digital format to optimize user access, flexibility, and convenience, aligned with the stated preference of the target user group [20]. Internet use is nearly ubiquitous in the United States among young adults (eg, $97 \%-100 \%$ ) with $77 \%$ of adults aged 18 to 29 years having home broadband service and $96 \%$ owning a smartphone [30-32]. A responsive design website was developed for the decision tool. This choice was made given the flexibility of adapting the layout and content across digital devices and the relative ease and low cost of website updates. A responsive design also provides a consistent user experience regardless of the operating system or device-desktop computer/laptop, tablet, or mobile phone.

\section{Steering Group}

A multidisciplinary steering group was assembled, which included clinicians and researchers with expertise in oncofertility and developing patient DAs (ie, oncologists, reproductive endocrinologists, psychologists, and nurses), a digital health communication researcher, an expert in user-centered design and usability testing, and a web developer. The team also included 4 patient research partners, who were asked for advice, provided feedback, and reviewed design decisions and content throughout the ideation phases and the entire development process.

\section{Results}

The following steps were taken to develop the prototype website of Roadmap to Parenthood. The tool was designed to be used by young adult female survivors of cancer who completed gonadotoxic treatment and were interested in future family building or were uncertain of their family-building plans. The primary purpose of the tool was to educate users about options to achieve parenthood after cancer (ie, natural conception, IVF or surrogacy with fresh/frozen/donated gametes, and adoption or fostering) and to guide value-based decision making and preparatory action toward family-building goals. 


\section{Identifying User Needs}

The first phase of user-centered design processes involves exploratory work to fully understand and define the problem, comprising literature reviews, end-user interviews and surveys, and team brainstorming [13]. We did much of this work previously, and user needs are described under preliminary studies. We also conducted a scoping review of the literature $[11,12]$ and discussed our understanding of user needs with our patient research partners. Common themes (eg, lack of information, uncertainty about reproductive survivorship care options, and a lack of awareness about high costs and legal complications) were reviewed by the research team, which led to brainstorming about how a web-based decision support and planning tool could address user needs (described in the following sections).

\section{Determination of Goals, Format, and Delivery}

From the start, the overall objective of the site was to help users become informed, clarify values and priorities with respect to family-building goals, and consider options for actionable preparatory behaviors (eg, pursuing a fertility evaluation or accessing social support). Family-building decision options included the possibility of natural conception and alternative options, that is, IVF, surrogacy, and adoption with subsidiary options (ie, use of fresh, frozen, or donor gametes and domestic or international adoption or fostering). Notably, personalized information about infertility risk and likelihood of success with family-building options could not be provided. Instead, the tool was built to increase awareness of the potential for challenges and benefits of early action and to prompt decisions about pursuing next steps aligned with parenthood goals. At the same time, we aimed to create a website that would feel empowering and would be usable, engaging, and effective. The tool was designed to be used independently by young adult female survivors of cancer and delivered via internet access using a responsive design format.

\section{Design Process}

We designed the DA website using an agile development process, which provided a nimble system for ongoing revision and iterative design decision making based on team review and input from the web developer, usability experts, and patient research partners. Modified beginning stage design sprints (ie, a rapid cycle user-centered prototype development and testing process [33]) were undertaken to generate and test ideas, obtain feedback, and iterate features of the prototype. Patient research partners were asked via email and phone/video communication for feedback and recommendations.

\section{Ideation Phase}

Ultimately, we wanted the website to be empowering for young women by supporting their family-building decision-making processes. A period of research and brainstorming was undertaken by the team with input from the web developer and patient research partners. We reviewed 9 publications reporting on 7 oncofertility patient DAs and were able to access 5 of the DAs available on the web (Multimedia Appendix 1). We looked for IPDAS DA components and descriptions of development processes. We discussed aspects we believed were useful, appealing, and should be considered for our own design and, conversely, aspects that we felt could be improved upon. For example, very dense text and long paragraphs prompted discussions about layout and content organization. It was also our aim to create a website that would feel approachable while conveying trustworthiness and reliability (ie, the personality of the website). A review of web-based oncofertility resources and women-targeted websites (Multimedia Appendix 1) focused on the esthetic appeal of designs and tonality. The websites rated most positively were those that felt clean and easy to use, with clear text and appealing use of graphics and white space. Fewer favorably reviewed websites included elements that felt stereotypically feminine (eg, too pink), content that felt crowded, or pages that had distracting visual designs such as overlaying text on busy backgrounds. Patient research partners were asked for feedback about the likes and dislikes and ideas for an appealing look and feel of DA and website esthetics. Tonality across DAs and websites ranged from professional and more business-like to friendly and more conversational. We aimed to strike a balance between friendly and approachable, yet informative and trustworthy.

We completed the discovery worksheet to facilitate communication and a shared understanding among team members about the overall objective for the site and initial stylistic ideas (Multimedia Appendix 2). For example, the 4 stylistic descriptors of the ideal website were empowering, informative, friendly, and clean. The web developer used the worksheet and descriptions of our likes/dislikes of the DA/website examples to understand the overall objective for the website and design, combined with user personas that provided further guidance.

\section{Personas and Storyboards}

On the basis of our background work [19-22], literature review [34], and clinical experience (Figure 2), 6 personas were created representing user types. The personas varied to represent different patient situations based on sociodemographic characteristics, cancer, and reproductive health factors. These factors were used to construct an overall picture of user archetypes and the kinds of questions, concerns, intentions, and goals they would have to interact with the website. Each persona was given a name, sociodemographic descriptors, a cancer story, social context, and description of values, priorities, and goals related to family building. Personas depicted the types of users for which the website was being designed and the scope of user intentions and needs. Decisions about design, features, and navigation were made to meet the needs of all user personas, in combination with the discovery worksheet. 
Figure 2. Personas depicting "user types" for the decision aid and planning tool website. Shortened versions of personas are depicted. IVF: in vitro fertilization.

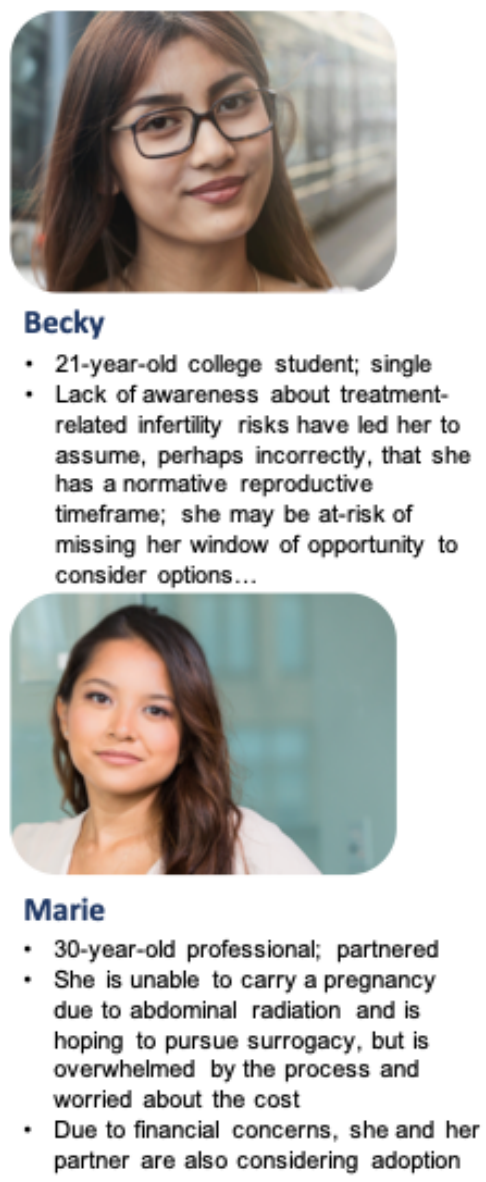

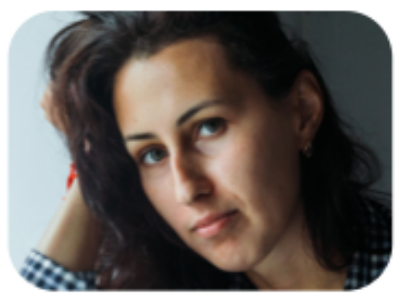

Alison

- 25-year-old college student; partnered

- She feels too young to have children now, but also feels anxious about her fertility; she tries to avoid fertility thoughts to reduce distress and has not had her fertility evaluated due to fear of receiving bad news...

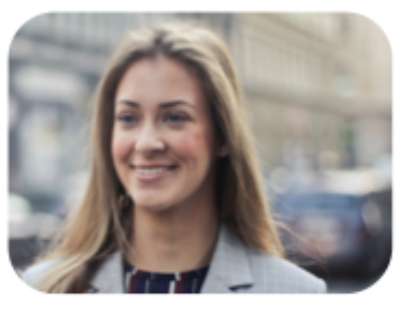

Jessica

- 38-year-old, unemployed; married

- She is still recovering emotionally from her cancer experience, yet is also worried about her age and declining fertility; believes she may be ok with adoption if pregnancy is not possible but feels uncertain...

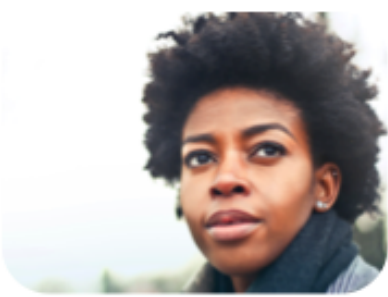

Tania

- 35-year-old professional; married

- She froze one embryo prior to her treatment and plans to pursue IVF soon, which her hopes and dreams for motherhood focused on her one "frozen baby," and overestimates the chance for success..

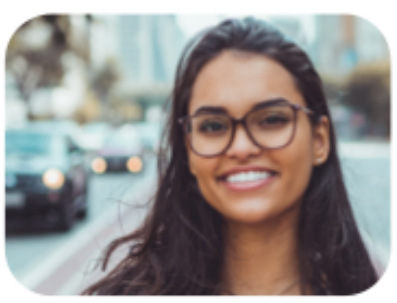

Justine

- 18-year-old college student; single

- Completed treatment as a young child and is non-compliant with survivorship care; thus has not received fertility counseling and assumes advances in technology will solve any fertility problems she may experience..
Storyboarding was used in conjunction with persona mapping to envision the end-to-end user experience of someone engaging with the site over time. This process mapped how the website would fit into a user's life as well as in what context they would be seeking out and engaging with the site for the first time and in subsequent viewings. We based our storyboards on the lives of actual patients depicted through the personas, imagining their life experiences leading up to and after viewing the website. For example, a young woman in her early 20 s, not yet ready to have children but aware that she may be at risk for fertility problems in the future, may approach the website with curiosity to learn about her options and recommendations for reproductive health as a survivor of cancer. Alternatively, an older woman in her late 30s, who is ready to have a child and fearful that known fertility problems will prevent her from becoming a mother, may approach the site with greater anxiety and fear, concern about reproductive time pressure, and looking for guidance for immediate action and resources.

\section{User Journey Mapping}

User journey mapping involved envisioning the different ways in which users might navigate through our website. During the user journey mapping, it is important to consider what the user will be thinking, feeling, and doing as they engage with the website. The personas we created guided our vision for user journey options. For example, given our conceptualization of users having different levels of knowledge and decision-making readiness at the outset, we debated various options for progressing through the website. The goal of user journey mapping was to plan and optimize how users would move through the website, identify gaps in the user experience, and iteratively pivot to correct errors [35].

\section{User Content Control}

It was important to design the website giving users control over their user journey with freedom to access web pages that best matched their needs, as opposed to a more rigid user journey with a single preconceived path through content (ie, similar to paper-based resources in which there is only one path to access content by turning pages). Content control is intended to provide users with control over the order, detail, and type of evidence presented. Providing users greater content control is related to improved quality of decision making [36]. Conversely, tailoring content via preset frameworks has been shown to reduce decision-making quality, despite the intention that more personalized information will be delivered to the user [36,37]. On the basis of this research and as depicted in the personas and storyboarding, we sought to give users a greater control over their user journey to explore content and review material relevant to their situations and interests.

We imagined that some users would need to move linearly through the DA components, starting with education about fertility and cancer treatment effects and moving on to review information about family-building options, whereas others may be quite informed and ready for next steps (eg, questions to ask your doctor) and still others may wish to avoid information that 
is irrelevant or even upsetting if particular family-building options are no longer possible. We wanted to allow flexibility to navigate through the website to best meet different users' needs and motivations. One idea was to prompt users to answer a set of questions on the homepage with a branching logic to guide them to the best landing page, but this was discarded after initial mockups because of its complexity. Ultimately, we created an omnichannel user journey, or choose your own adventure design, in which users had control over the user journey and could easily see options for next step recommendations and click on webpages to access content that matched their needs, preferences, and decision-making readiness. The DA components were marked across the top navigation bar. Many pages included links at the bottom that suggested the next pages to visit but these could be ignored, and the user had control over which pages they visited. This was an iterative process designed to match users at different stages of decision making. We identified gaps in our initial design ideas and developed solutions to optimize the user experience.

\section{Information Architecture}

Following the development of user journeys, we moved into the information architecture phase of the project (Figure 3). This process involved leveraging the user flows to decide how content should be organized, structured, and labeled across the website pages. The main components of the information architecture process included finalizing decisions about categorizing and structuring information, labeling systems (ie, how information is represented), navigation systems (ie, how users would browse or move through information), and search systems (ie, how users would look for and find information). Various ways of organizing content and implications for the user journey have been discussed and debated. For example, multiple options were considered for how to best introduce and categorize family-building options and how to organize decision support content. As depicted in Figure 3, users had multiple options to move on from the homepage. The next step options were grouped together and introduced to users on a single page with links through which they could click for more content on each topic. Decisions about the information architecture guided content strategy and informed the design of the user interface, which was later used in wireframing and prototyping.

Figure 3. Depiction of the information architecture of the decision aid website. IPDAS: International Patient Decision Aid Society.

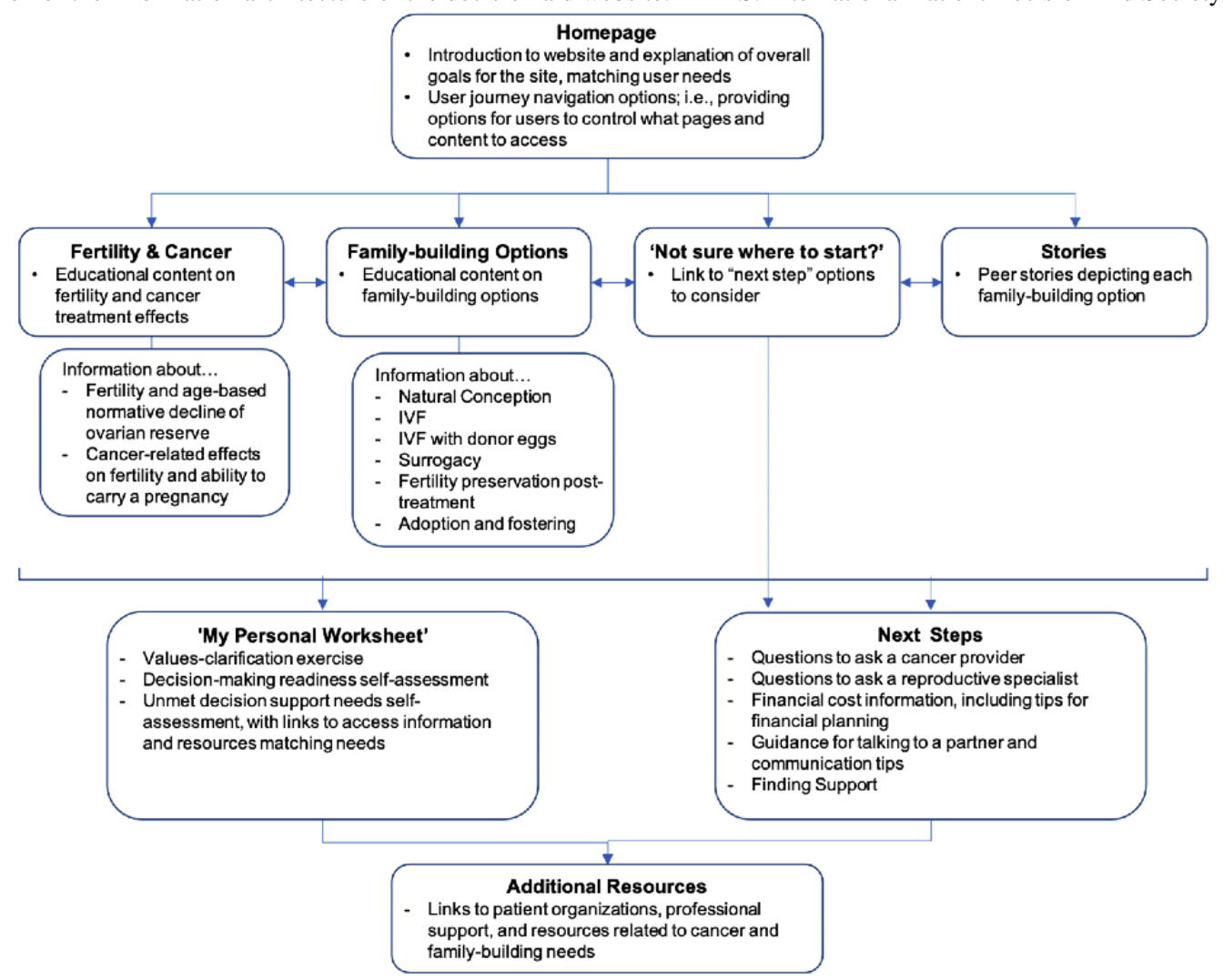

\section{Sketches and Wireframes}

The next step in our website development was to create sketches of our ideas and then wireframes. All appropriate web standards were used to develop content for the site. Our overarching goal with the content was to make it user-friendly and helpful to the reader. We placed special emphasis on using concrete examples that would be highly relevant to the reader. Initial sketches were made by the study team via pen and paper and dry-erase white boards, and ideas were discussed with the web developer. Wireframes (ie, two-dimensional models of the website interface) focused on content presentation and space allocation, functionalities of the site, and intended behaviors of the user [38]. They were used to give the team a sense of how the site would be organized and function once it was fully developed, without focusing on styling, color, and graphics. These digital wireframes allowed us to collect early feedback from collaborators and patient research partners and led to multiple 
iterations of website wireframes. Patient research partners were critical at this juncture to clearly understand the purpose of the website, comment on available content, design esthetic upfront, and appropriate navigation that would support their decision-making needs. Once the basic wireframes were set, more detailed illustrations were created using static images to depict the look and feel of the site, such as color palettes, font choices, and pictures. They discussed the emotional experiences that users might have when approaching the website, based on the stress and uncertainty of fertility and family-building futures, and cited a desire for the website to feel calming and hopeful. Wireframes were informed by this feedback and the work done during the discovery phase.

\section{Aligning on a Design Aesthetic}

It is recommended to use images that end users will find to be realistic and relatable when designing health- and medicine-related content [29]. Research suggests users of digital health tools may prefer photographs of real people, as opposed to illustrations or no photographs at all [39]. It is also important to show people of diverse backgrounds, allowing more people to find themselves and relate to the content [40]. Accordingly, we included photographic images of young women representing different races, ethnicities, and ages throughout the site. There were no medical or fertility-related photographs. To facilitate understanding, whenever possible, we accompanied written text with graphs (eg, a line graph depicting the decline in ovarian reserve over time) and comparison charts (eg, a table with the costs of family-building options listed side by side). Each family-building option had a different icon to guide the user's journey and comprehension. The research team developed an initial conceptualization of photos, icons, and graphs based on the dual goals of optimizing usability and achieving the desired stylistic feel, and patient research partners were asked for their impressions. Generally, feedback was positive; however, designs were modified based on specific suggestions (eg, to use a different photo or improve labeling). One key issue was how to best depict potentially distressing information. In particular, patient research partners told us that seeing the downward slope of the line graph showing a declining ovarian reserve over time was a powerful and potentially upsetting image. The pros and cons of conveying this information in text or graphs were discussed. Ultimately, with agreement from our patient research partners, we decided to keep the graph for its effectiveness in displaying the critical information. We will test these design decisions and their emotional impact during usability testing.

\section{Content Development}

In developing the narrative for the website, guidelines for developing web-based informational content were followed [41]. Writing user-friendly content for a website involves consideration of word choice (eg, use of plainlanguage and keywords known to users and an active voice), use of short sentences and paragraphs, chunking content and presenting information in bullets and numbered lists, use of clearly distinguished headlines and subheadings, placement of key informational pieces on the page, and use of white space $[41,42]$. We followed the plain language checklist for writing website content (Textbox 1; adapted from the checklist developed by the National Institutes of Health [NIH; 43]). Definitions of medical terminology were provided, and simpler medical terms were used whenever possible. For example, the title ask a fertility specialist replaced ask a reproductive endocrinologist, and the definition for a reproductive endocrinologist was provided for reference.

Textbox 1. Plain language checklist for writing for the web.

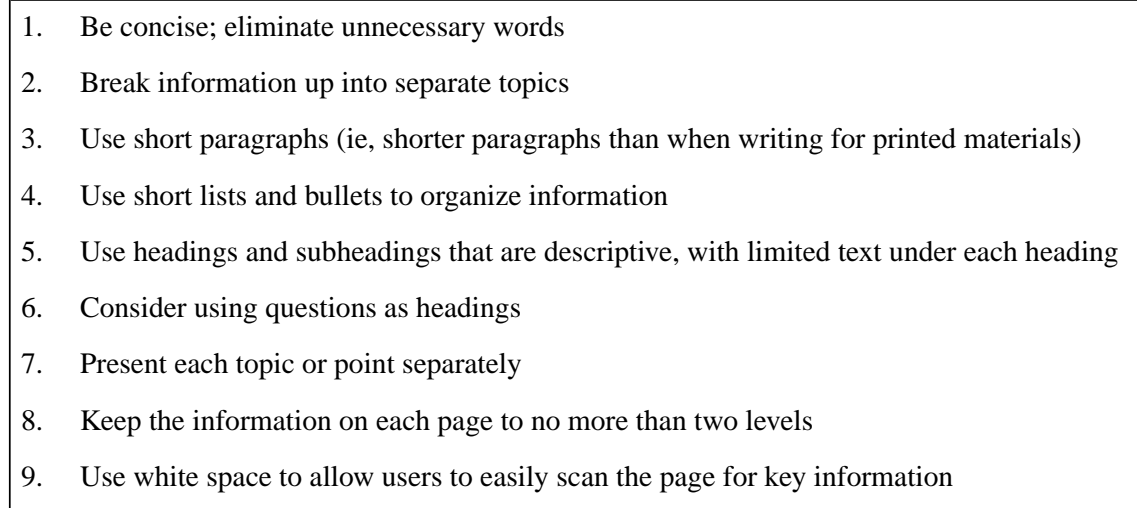

10. Write using the same words users would use when doing a web search for the information, particularly for page titles and headings

11. Clearly explain things such that each page can stand on its own; ie, don't assume users will have knowledge of the subject or have read other content/pages on the site

12. Use language to guide the user journey that describes what the user will get if they click on the link; ie, never use "click here" as a link

13. Eliminate unnecessary words as much as possible

Content was also written to be all-inclusive with respect to user diversity, particularly regarding partnership status (ie, single vs coupled users), sexual orientation (ie, users identifying as lesbian, gay, bisexual, transgender, and queer/questioning [LGBTQ]), and definitions of family makeup (eg, same-sex parents and single women pursuing parenthood). Users were not assumed to have a partner (now or when pursuing family building), and partners were not assumed to be of a specific gender. Listed resources provided access to more detailed information (eg, state-by-state laws regulating LGBTQ and 
same-sex couple adoption, legal advocacy, and financial grant opportunities for LGBTQ prospective parents). Religious and cultural factors that may impact users' decision making, particularly with respect to the use of reproductive medicine (eg, transvaginal procedures and creation of embryos in the lab), were addressed in a limited way at several points throughout the website. For example, users are prompted to consider religious, cultural, and ethical beliefs in relation to their decision-making options in the values clarification exercise and can also reflect on these factors when answering open-ended questions.

\section{Additional Design Considerations}

Patient research partners discussed the emotional experiences that users might have when approaching the website, based on the stress and uncertainty of fertility and family-building futures, and cited a desire for the website to feel calming and hopeful. Several design considerations were made to reflect the emotional experiences and health literacy levels of users interacting with the site.

\section{Designing for Iterative Decision Making}

Most patient DAs for health care decisions involve discrete periods in which a single decision about treatment options must be made [43]. DAs developed in cancer and fertility have almost exclusively focused on pretreatment fertility preservation in which there are 2 decision options (yes or no) and a limited time window, as cancer treatment must be initiated $[12,44]$. Conversely, decision making about family building may involve a more complex set of decision points. For example, for some users, the focus of the decision may be about seeing a fertility specialist, and decision options may change based on feedback about reproductive viability and the likelihood of success with natural pregnancy, IVF, or surrogacy, thus changing their informational and support needs. Many survivors may first prioritize having a biologically related child, but if given a low chance for success, they may re-evaluate their priorities and choose to spend financial resources on pursue adoption. Others may restart the decision process if they are unsuccessful, such as after failed IVF attempts, or if the challenges become too great. Single women may change their preferences when they involve a decision partner. On the basis of this conceptualization of longitudinal decision-making processes, the design of the website included support for iterative engagement such that the information architecture was set up to allow users to have maximum control over the user journey and easily circle back to content about alternative family-building options.

\section{Emotional Design}

Our previous work suggested that women who experienced more intense emotions of distress and fear often described lower self-efficacy to manage risks and, at the most extreme, avoidance of fertility information and disengagement from decision-making processes [19]. These findings are consistent with the research delineating the impact of affective states on medical decision making and behavior, such that anxiety and fear tend to lead individuals to prioritize short-term gratification over long-term goals $[45,46]$. In this case, young women who are distressed about infertility risks or fear of receiving bad news may avoid information to avoid further distress (thus prioritizing short-term relief), diminishing their chances of achieving long-term goals for parenthood. One of the objectives for the website was to be empowering for young women, for example, to guide users in becoming informed and setting realistic expectations about potential challenges, while inspiring hope and optimism that parenthood may be achieved. With consultation and input from experts on the team, we aimed to achieve this emotional experience for users through design decisions about tonality, color, language, and picture selection. Acknowledging that information on the website may be upsetting for users, we made decisions about design and photo images to create a positive user experience (eg, facial expressions of women in photos that suggest confidence, hope, and optimism), without negating the difficulties and negative emotions users may experience as a part of this journey. We also used color and design to facilitate comprehension and guide engagement with the site. We attempted to avoid design elements that might overwhelm users, perhaps leading them to abandon the website. For example, large blocks of text can be difficult to read and comprehend, which may be even more challenging for cancer survivors with lasting treatment side effects such as fatigue or cognitive impairment [47], and our patient research partners corroborated concerns about information overload and text-heavy pages. Efforts to reduce the cognitive load and emotional distress included using short text blocks, white space, clearly identified and defined terminology, and graphs, charts, and icons.

\section{Guidelines and Standards}

The website was designed to meet varying health literacy and reading levels of users and in accordance with the IPDAS guidelines and the Ottawa Decision Support Framework for developing patient DAs [25,26,48], and health literacy guidelines, including those set by the NIH [49,50]. The Centers for Medicaid and Medicare Services toolkit for making written material clear and effective was also employed [51]. The IPDAS checklist is presented in Table 1, whereas the Health Literacy Online Strategies Checklist is presented in Table 2. Standards required for the design and development of websites affiliated with the US Department of Health and Human Services were also reviewed and used to guide design decisions [52]. Guidelines from the Office of Disease Prevention and Health Promotion [49], NIH [50], and the Centers for Medicare and Medicaid Services [51] for designing digital health websites and information tools for low health literacy and culturally diverse populations were also followed. 
Table 1. Review of the Roadmap to Parenthood patient decision aid using the International Patient Decision Aid Standards quality checklist.

\begin{tabular}{lll}
\hline Criteria & Answer
\end{tabular}

Criteria to be defined as a patient $\mathrm{DA}^{\mathrm{a}}$

1. The DA describes the condition related to the decision $\quad$ Yes

2. The DA describes the decision that needs to be considered $\quad$ Yes

3. The DA identifies the target audience Yes

4. The DA lists the options (health care or other) Yes

5. The DA has information about the positive features of the options (eg, benefits or advantages) Yes

6. The DA has information about the negative features of the options (eg, harms, side effects, or disadvantages) Yes

7. The DA helps patients clarify their values for outcomes of options by (a) asking people to think about which positive Yes and negative features of the options matter most to them AND/OR (b) describing each option to help patients imagine the physical, social, and/or psychological effects ${ }^{\mathrm{b}}$

8. The DA makes it possible to compare the positive and negative features of the available options Yes

9. The DA shows the negative and positive features of the options with equal detail Yes

10. The DA compares probabilities (eg, chance of a disease, benefit, harm, or side effect) of options using the same denom- N/A ${ }^{\mathrm{c}, \mathrm{d}}$ inator

11. The DA (or available technical documents) reports funding sources for development Yes

12. The DA reports whether authors of the DA or their affiliations stand to gain or lose by choices people make after using Yes the DA

13. The DA includes authors/developers' credentials or qualifications $\quad$ Yes

14. The DA reports the date when it was last updated $\quad$ Yes

15. The DA (or available technical document) reports readability levels $\quad$ Yes

16. The DA provides references to scientific evidence used $\quad$ Yes

\section{Other criteria for Das about screening or testing}

17. The DA has information about what the test is designed to measure $\quad \mathrm{Yes}^{\mathrm{e}}$

18. The DA describes possible next steps based on the test results $\quad \mathrm{Yes}^{\mathrm{e}}$

19. The DA has information about the chances of disease being found with and without screening Yes ${ }^{\mathrm{e}}$

20. The DA has information about detection and treatment of disease that would never have caused problems if screening Yes ${ }^{\mathrm{e}}$ had not been done

\section{Other criteria indicating quality}

21. The DA describes what happens in the natural course of the condition (health or other) if no action is taken Yes

22. The DA has information about the procedures involved (eg, what is done before, during, and after the health care option) Yes

23 The information about outcomes of options (positive and negative) includes the changes that may happen N/A

24. The DA presents probabilities using event rates in a defined group of people for a specified time N/A

25. The DA compares probabilities of options over the same period of time N/A

26. The DA uses the same scales in diagrams comparing options $\quad$ Yes

27. Users (people who previously faced the decision) were asked what they need to prepare them to discuss a specific de- Yes cision

28. The DA was reviewed by people who previously faced the decision and were not involved in the DA's development Yes and field testing

29. People who were facing the decision field tested the DA

$\mathrm{No}^{\mathrm{f}}$

30. Field testing showed that the DA was acceptable to users (the general public and practitioners)

31. Field testing showed that people who were undecided felt that the information was presented in a balanced way

$\mathrm{No}^{\mathrm{f}}$

$\mathrm{No}^{\mathrm{f}}$

32. There is evidence that the DA (or one based on the same template) helps people know about the available options and $N / \mathrm{A}^{\mathrm{g}}$ their features 
33. There is evidence that the DA (or one based on the same template) improves the match between the features that matter $\quad N / A^{g}$ most to the informed person and the option that is chosen

${ }^{\mathrm{a} D A}$ : decision aid.

${ }^{b}$ We expanded this definition to also include financial effects of decision option outcomes.

${ }^{\mathrm{c}} \mathrm{N} / \mathrm{A}$ : not applicable.

${ }^{d}$ The primary purpose of the decision aid is to educate and support patients facing limited family-building options in which it is not possible to predict the likelihood of success or failure with in vitro fertilization, surrogacy, and adoption.

${ }^{\mathrm{e}}$ The decision aid and planning tool provides information on infertility risk due to gonadotoxic cancer treatment, options to test fertility, and possible next steps for family building based on the results of fertility testing and indications of reproductive potential; however, this is only one aspect of the entire decision-making process encompassing family building after cancer.

${ }^{\mathrm{f}}$ This criterion was not yet relevant, as the patient decision aid was still in development. Usability and field testing are currently underway.

${ }^{\mathrm{g}}$ Study of efficacy will begin after the completion of usability and field testing and once the design of the decision aid is finalized. 
Table 2. Review of the Roadmap to Parenthood patient decision aid using the Health Literacy Online Strategies Checklist from the National Institutes of Health.

\begin{tabular}{lr}
\hline Criteria & Ans \\
\hline Write actionable content & Yes \\
1. Identify user motivations and goals & Yes \\
2. Put the most important information first & Yes \\
3. Describe the health behavior [information] - just the basics & Yes \\
4. Stay positive. Include the benefits of taking action & Yes \\
5. Provide specific action steps & Yes \\
6. Write in plain language & Yes \\
7. Check content for accuracy &
\end{tabular}

\section{Display content clearly on the page}

$\begin{array}{lr}\text { 8. Limit paragraph size. Use bullets and short lists } & \text { Yes }\end{array}$

9. Use meaningful headings $\quad$ Yes

10. Use readable font $\quad$ Yes

$\begin{array}{lc}\text { 11. Use white space and avoid clutter } & \text { Yes }\end{array}$

12. Keep the most important content above the fold - even on mobile $\quad$ Yes

13. Use links effectively $\quad$ Yes

14. Use color or underline to identify links $\quad$ Yes

15. Use Images that help people learn $\quad$ Yes

16. Use appropriate contrast $\quad$ Yes

$\begin{array}{ll}\text { 17. Make web content printer-friendly } & \text { Yes }\end{array}$

18. Make your site accessible to people with disabilities Yes $^{\mathrm{a}}$

19. Make websites responsive $\quad$ Yes

20. Design mobile content to meet mobile users' needs $\quad$ Yes

\section{Organize content and simplify navigation}

21. Create a simple and engaging homepage $\quad$ Yes

22. Label and organize content with your users in mind $\quad$ Yes

23. Create linear information paths $\quad$ Yes $^{b}$

24. Give buttons meaningful labels $\quad$ Yes

25. Make clickable elements recognizable $\quad$ Yes

26. Make sure the browser "back" button works $\quad$ Yes

27. Provide easy access to home and menu pages $\quad$ Yes

28. Give users options to browse $\quad$ Yes

29. Include a simple search function $\quad \mathrm{No}^{\mathrm{c}}$

30. Display search results clearly $\quad \mathrm{No}^{\mathrm{c}}$

\section{Engage users}

$\begin{array}{lr}\text { 31. Share information through multimedia } & \text { No }\end{array}$

32. Design intuitive interactive graphics and tools $\quad$ Yes

33. Provide tailored information $\quad$ Yes $^{\mathrm{d}}$

34. Create user-friendly forms and quizzes $\quad$ Yes

35. Consider social media sharing options $\quad$ N/A ${ }^{\text {e,f }}$ 


\begin{tabular}{lcl}
\hline Criteria & Answer \\
\hline 36. Recruit users with limited literacy skills and limited health literacy skills & No $^{\mathrm{f}}$ \\
37. Identify and eliminate logistical barriers to participation & Yes \\
38. Create plain language testing materials & Yes \\
39. Test whether your content is understandable and actionable & No $^{\mathrm{f}}$ \\
40. Use moderators who have experience with users with limited literacy skills & N/A \\
\hline
\end{tabular}

${ }^{\text {a }}$ Design decisions were made within the scope of the project to make content accessible to people with disabilities, including using large font and white space.

${ }^{b}$ Beginning sections of the decision aid tool were designed so that users would follow a linear path to obtain information about fertility, infertility risks associated with cancer, and family-building options. Following this, users were prompted to choose their own path with respect to which content was most applicable to their situation and needs (eg, finding support vs financial planning strategies).

${ }^{\mathrm{c}}$ We were unable to include a search function due to the limitations of web development resources.

${ }^{\mathrm{d}}$ Information was tailored to the extent that users had control over content they viewed because of the choose your own path click-through user journey design of the website, use of a drawer design to hide/reveal content based on user interest, and available drop-down features.

${ }^{\mathrm{e}} \mathrm{N} / \mathrm{A}$ : not applicable.

${ }^{\mathrm{f}}$ This criterion was not yet relevant, as the patient decision aid was still in development.

${ }^{g}$ The tool is designed to be used by young adult female cancer survivors independently, without help from moderators, clinicians, or professionals to provide guidance or decision support. Future work will explore options for use of the tool during patient-provider interactions and for shared decision making.

\section{Discussion}

User-centered design practices involve an extensive and iterative process of designing and developing solutions from the perspective of the end user. The development of the Roadmap to Parenthood prototype was based on pilot work to understand the experiences and needs of young adult female survivors of cancer related to family building after cancer, combined with a collaborative, multidisciplinary team approach to making initial design decisions that would best meet their needs. Ultimately, usability testing with members of the target patient population is necessary to determine whether design decisions have been made to optimize the ease of use, comprehension, and usefulness of the product or whether improvements are needed. Once completed, we hope that this DA for family building after cancer will be a complementary resource to the DAs and resources that exist for pretreatment fertility preservation [11,12]. We followed similar development procedures to those reported for other DAs in the literature, including adherence to IPDAS guidelines, review of previously published DAs, use of a multidisciplinary team approach, iterative design with feedback from target users, and digital platforms [53-57]. Fertility preservation DAs have been shown to be acceptable and beneficial to young adult female cancer survivors [53,55,57], suggesting the DA presented here may similarly support patients through the next steps of family building.

The early design considerations presented here are important steps for developing a user-centered prototype that is a good starting point for usability testing. We are currently underway in conducting usability testing with target end users to obtain feedback about the website prototype. This process involves quantitative and qualitative data analytic approaches using standardized usability testing procedures including think-aloud sessions and validated usability assessment measures. Design modifications and additional testing will be conducted until user feedback indicates that we have optimized the product design with the appropriate degree of compassion and empathy. Following usability testing, we will conduct a single-arm pilot study to test the tool as a DA intervention for family building after cancer [58]. For this study, we will follow the SUNDAE Checklist (Standards for UNiversal reporting of patient Decision Aid Evaluations) for reporting patient DA evaluative studies [48]. Future directions of this research will also explore how the tool may be used for dyadic decision making, including users' partners, and as a part of cancer survivorship care to support patient-provider communication and shared decision making.

\section{Limitations and Future Directions}

There were limitations to this study. One of our most difficult tasks in creating the website was to balance the amount of informational content with concerns about information overload, an issue that was brought up by our patient research partners. Although the website provides a comprehensive overview of fertility and family-building topics and multiple aspects of decision-making support, some subsidiary topics were not as thoroughly reviewed. For example, while users are prompted to self-reflect and explore personal factors that are most relevant to their decisions, in-depth content specific to cultural and religious factors was limited. Similarly, this version of the website does not mention step-motherhood as a family-building option. Future usability testing will determine whether more comprehensive information is needed on these topics. In addition, while we decided to build a web-based resource to increase access and convenience among the target user group of young adult women who reported a preference for digital resources, we recognize that some members of the target population may not have regular or dependable access to the internet. However, we do not believe this is a widespread issue, based on the data gathered on internet accessibility across various demographic cohorts [30-32]. In order to accommodate users who may prefer a paper-based version, we included a print 
button on the top of each page that autoformats the website content for the ease of printing.

\section{Conclusions}

Following this first phase of the development process of a patient DA and planning tool for family building after cancer, our subsequent usability testing phase will guide modifications and finalization of the design. This clinical research will contribute to a priority area set forth by the NCI and the American Society of Clinical Oncology to develop age-specific resources for young adult cancer survivors while leveraging the advantages of digital communication technology $[59,60]$.

\section{Acknowledgments}

Research reported in this publication was supported by the NCI of the NIH under award number K07CA229186. The content is solely the responsibility of the authors and does not necessarily represent the official views of the NIH. The authors would also like to thank their patient research partners and young adult cancer patient organizations for their collaboration (Stupid Cancer, Lacuna Loft, The Samfund, and Gryt Health).

\section{Conflicts of Interest}

None declared.

\section{Multimedia Appendix 1}

List of oncofertility patient decision aids, online resources, and websites reviewed during the ideation phase of website development. [DOCX File, 33 KB-Multimedia Appendix 1]

\section{Multimedia Appendix 2}

Discovery worksheet for initial website design.

[DOCX File, 14 KB-Multimedia Appendix 2]

\section{References}

1. Institute of Medicine Committee on Quality of Health Care in America. Crossing the Quality Chasm: A New Health System for the 21st Century. Washington, DC: National Academies Press; 2001.

2. Rathert C, Wyrwich MD, Boren SA. Patient-centered care and outcomes: a systematic review of the literature. Med Care Res Rev 2013 Aug;70(4):351-379. [doi: 10.1177/1077558712465774] [Medline: 23169897]

3. Gorman JR, Bailey S, Pierce JP, Su HI. How do you feel about fertility and parenthood? The voices of young female cancer survivors. J Cancer Surviv 2012 Jun;6(2):200-209 [FREE Full text] [doi: 10.1007/s11764-011-0211-9] [Medline: 22179785]

4. Armuand GM, Wettergren L, Rodriguez-Wallberg KA, Lampic C. Women more vulnerable than men when facing risk for treatment-induced infertility: a qualitative study of young adults newly diagnosed with cancer. Acta Oncol 2015 Feb;54(2):243-252. [doi: 10.3109/0284186X.2014.948573] [Medline: 25140859]

5. Gargus E, Deans R, Anazodo A, Woodruff TK. Management of primary ovarian insufficiency symptoms in survivors of childhood and adolescent cancer. J Natl Compr Canc Netw 2018 Sep;16(9):1137-1149 [FREE Full text] [doi: 10.6004/jnccn.2018.7023] [Medline: 30181423]

6. Benedict C, Thom B, N Friedman D, Diotallevi D, M Pottenger E, J Raghunathan N, et al. Young adult female cancer survivors' unmet information needs and reproductive concerns contribute to decisional conflict regarding posttreatment fertility preservation. Cancer 2016 Jul 1;122(13):2101-2109 [FREE Full text] [doi: 10.1002/cncr.29917] [Medline: 27213483]

7. Murphy D, Klosky JL, Reed DR, Termuhlen AM, Shannon SV, Quinn GP. The importance of assessing priorities of reproductive health concerns among adolescent and young adult patients with cancer. Cancer 2015 Aug 1;121(15):2529-2536 [FREE Full text] [doi: 10.1002/cncr.29466] [Medline: 26054052]

8. Gorman JR, Drizin JH, Smith E, Flores-Sanchez Y, Harvey SM. Patient-centered communication to address young adult breast cancer survivors' reproductive and sexual health concerns. Health Commun 2020 Jul 23:1-16. [doi: 10.1080/10410236.2020.1794550] [Medline: 32703034]

9. Stacey D, Kryworuchko J, Belkora J, Davison BJ, Durand M, Eden KB, et al. Coaching and guidance with patient decision aids: a review of theoretical and empirical evidence. BMC Med Inform Decis Mak 2013;13(Suppl 2):S11 [FREE Full text] [doi: 10.1186/1472-6947-13-S2-S11] [Medline: 24624995]

10. Hoffman AS, Volk RJ, Saarimaki A, Stirling C, Li LC, Härter M, et al. Delivering patient decision aids on the internet: definitions, theories, current evidence, and emerging research areas. BMC Med Inform Decis Mak 2013;13(Suppl 2):S13 [FREE Full text] [doi: 10.1186/1472-6947-13-S2-S13] [Medline: 24625064]

11. Speller B, Sissons A, Daly C, Facey M, Kennedy E, Metcalfe K, et al. An evaluation of oncofertility decision support resources among breast cancer patients and health care providers. BMC Health Serv Res 2019 Feb 6;19(1):101 [FREE Full text] [doi: 10.1186/s12913-019-3901-z] [Medline: $\underline{\text { 30728004] }}$ 
12. Wang Y, Anazodo A, Logan S. Systematic review of fertility preservation patient decision aids for cancer patients. Psychooncology 2019 Mar;28(3):459-467. [doi: 10.1002/pon.4961] [Medline: 30523651]

13. Improving the User Experience. US Department of Health \& Human Services. 2013. URL: https://www.usability.gov/ [accessed 2019-05-24]

14. Slater H, Campbell JM, Stinson JN, Burley MM, Briggs AM. End user and implementer experiences of mhealth technologies for noncommunicable chronic disease management in young adults: systematic review. J Med Internet Res 2017 Dec 12;19(12):e406 [FREE Full text] [doi: 10.2196/jmir.8888] [Medline: 29233804]

15. Harst L, Lantzsch H, Scheibe M. Theories predicting end-user acceptance of telemedicine use: systematic review. J Med Internet Res 2019 May 21;21(5):e13117 [FREE Full text] [doi: 10.2196/13117] [Medline: $\underline{\text { 31115340] }}$

16. Darlow S, Wen K. Development testing of mobile health interventions for cancer patient self-management: a review. Health Informatics J 2016 Sep;22(3):633-650 [FREE Full text] [doi: 10.1177/1460458215577994] [Medline: 25916831]

17. Leventhal H, Phillips LA, Burns E. The Common-Sense Model of Self-Regulation (CSM): a dynamic framework for understanding illness self-management. J Behav Med 2016 Dec;39(6):935-946. [doi: 10.1007/s10865-016-9782-2] [Medline: 27515801]

18. Diefenbach MA, Leventhal $\mathrm{H}$. The common-sense model of illness representation: theoretical and practical considerations. J Social Distress Homeless 2016 Jul 7;5(1):11-38. [doi: 10.1007/bf02090456]

19. Benedict C, Hahn AL, McCready A, Kelvin JF, Diefenbach M, Ford JS. Toward a theoretical understanding of young female cancer survivors' decision-making about family-building post-treatment. Support Care Cancer 2020 Oct;28(10):4857-4867. [doi: 10.1007/s00520-020-05307-1] [Medline: 31993754]

20. Benedict C, Nieh J, Hahn AL, McCready A, Diefenbach M, Ford JS. Looking at future cancer survivors, give them a roadmap: addressing fertility and family-building topics in post-treatment cancer survivorship care. Support Care Cancer 2020 Sep 5:- epub ahead of print. [doi: 10.1007/s00520-020-05731-3] [Medline: 32889581]

21. Benedict C, Shuk E, Ford JS. Fertility issues in adolescent and young adult cancer survivors. J Adolesc Young Adult Oncol 2016 Mar;5(1):48-57 [FREE Full text] [doi: 10.1089/jayao.2015.0024] [Medline: 26812452]

22. Benedict C, McLeggon J, Thom B, Kelvin JF, Landwehr M, Watson S, et al. 'Creating a family after battling cancer is exhausting and maddening': Exploring real-world experiences of young adult cancer survivors seeking financial assistance for family building after treatment. Psychooncology 2018 Dec;27(12):2829-2839 [FREE Full text] [doi: 10.1002/pon.4898] [Medline: 30238545]

23. Halliday LE, Boughton MA. Exploring the concept of uncertain fertility, reproduction and motherhood after cancer in young adult women. Nurs Inq 2011 Jun;18(2):135-142. [doi: 10.1111/j.1440-1800.2011.00532.x] [Medline: 21564394]

24. Mac Dougall K, Beyene Y, Nachtigall RD. Age shock: misperceptions of the impact of age on fertility before and after IVF in women who conceived after age 40. Hum Reprod 2013 Feb;28(2):350-356 [FREE Full text] [doi: 10.1093/humrep/des409] [Medline: 23203214]

25. Coulter A, Stilwell D, Kryworuchko J, Mullen PD, Ng CJ, van der Weijden T. A systematic development process for patient decision aids. BMC Med Inform Decis Mak 2013;13(Suppl 2):S2 [FREE Full text] [doi: 10.1186/1472-6947-13-S2-S2] [Medline: 24625093]

26. Decision Aid Toolkit - Patient Decision Aids. Ottawa Hospital Research Institute. URL: https://decisionaid.ohri.ca/resources. $\underline{\text { html }}$ [accessed 2019-06-04]

27. Elwyn G, O'Connor A, Stacey D, Volk R, Edwards A, Coulter A, International Patient Decision Aids Standards (IPDAS) Collaboration. Developing a quality criteria framework for patient decision aids: online international Delphi consensus process. Br Med J 2006 Aug 26;333(7565):417 [FREE Full text] [doi: 10.1136/bmj.38926.629329.AE] [Medline: 16908462]

28. Durand M, Witt J, Joseph-Williams N, Newcombe RG, Politi MC, Sivell S, et al. Minimum standards for the certification of patient decision support interventions: feasibility and application. Patient Educ Couns 2015 Apr;98(4):462-468. [doi: 10.1016/j.pec.2014.12.009] [Medline: 25577469]

29. HHS Web Standards Usability Guidelines. US Department of Health and Human Services. URL: https://www.hhs.gov/ [accessed 2019-05-24]

30. Demographics of Internet and Home Broadband Usage in the United States. Pew Research Center. 2019. URL: https://www. pewresearch.org/internet/fact-sheet/internet-broadband/ [accessed 2020-08-13]

31. Demographics of Mobile Device Ownership and Adoption in the United States. Pew Research Center. URL: https://www. pewresearch.org/internet/fact-sheet/mobile/ [accessed 2019-12-04]

32. Pew Research Center. URL: https://www.pewresearch.org/internet/2018/05/31/teens-social-media-technology-2018/ [accessed 2019-11-24]

33. Banfield R, Lombardo C, Wax T. Design Sprint: A Practical Guidebook for Building Great Digital Products. Canada: O'Reily Media, Inc; 2015.

34. Logan S, Perz J, Ussher JM, Peate M, Anazodo A. A systematic review of patient oncofertility support needs in reproductive cancer patients aged 14 to 45 years of age. Psychooncology 2018 Feb;27(2):401-409. [doi: 10.1002/pon.4502] [Medline: 28734119]

35. Journey Mapping 101. Nielsen Norman Group. URL: https://www.nngroup.com/articles/journey-mapping-101/ [accessed 2020-10-15] 
36. Syrowatka A, Krömker D, Meguerditchian AN, Tamblyn R. Features of computer-based decision aids: systematic review, thematic synthesis, and meta-analyses. J Med Internet Res 2016 Jan 26;18(1):e20 [FREE Full text] [doi: 10.2196/jmir.4982] [Medline: 26813512]

37. Scherer LD, Ubel PA, McClure J, Greene SM, Alford SH, Holtzman L, et al. Belief in numbers: When and why women disbelieve tailored breast cancer risk statistics. Patient Educ Couns 2013 Aug;92(2):253-259 [FREE Full text] [doi: 10.1016/j.pec.2013.03.016] [Medline: 23623330]

38. Improving the User Experience: Wireframing. Department of HealthHuman Services Digital Communications Division. URL: https://www.usability.gov/how-to-and-tools/methods/wireframing.html [accessed 2019-08-07]

39. Cyr, Head, Larios, Pan. Exploring human images in website design: a multi-method approach. MIS Q 2009;33(3):539. [doi: $10.2307 / 20650308]$

40. Health Literacy Online: A Guide to Simplifying the User Experience. Office of Disease Prevention and Health Promotion (ODPHP). 2016. URL: https://health.gov/healthliteracyonline/ [accessed 2019-08-07]

41. Improving the User Experience: Writing for the Web. Office of Disease Prevention and Health Promotion (ODPHP). URL: https://www.usability.gov/how-to-and-tools/methods/writing-for-the-web.html [accessed 2019-08-07]

42. How to Present Scientific Findings Online. Nielsen Norman Group. URL: https://www.nngroup.com/articles/ scientific-findings-online/ [accessed 2019-08-07]

43. Stacey D, Légaré F, Lewis K, Barry MJ, Bennett CL, Eden KB, et al. Decision aids for people facing health treatment or screening decisions. Cochrane Database Syst Rev 2017 Apr 12;4:CD001431 [FREE Full text] [doi: 10.1002/14651858.CD001431.pub5] [Medline: 28402085]

44. Speller B, Micic S, Daly C, Pi L, Little T, Baxter NN. Oncofertility decision support resources for women of reproductive age: systematic review. JMIR Cancer 2019 Jun 6;5(1):e12593 [FREE Full text] [doi: 10.2196/12593] [Medline: 31199289]

45. Loewenstein G. Hot-cold empathy gaps and medical decision making. Health Psychol 2005 Jul;24(4S):S49-S56. [doi: 10.1037/0278-6133.24.4.S49] [Medline: 16045419]

46. Loewenstein GF, Weber EU, Hsee CK, Welch N. Risk as feelings. Psychol Bull 2001 Mar;127(2):267-286. [doi: 10.1037/0033-2909.127.2.267] [Medline: 11316014]

47. Micaux Obol C, Lampic C, Wettergren L, Ljungman L, Eriksson LE. Experiences of a web-based psycho-educational intervention targeting sexual dysfunction and fertility distress in young adults with cancer-A self-determination theory perspective. PLoS One 2020;15(7):e0236180 [FREE Full text] [doi: 10.1371/journal.pone.0236180] [Medline: 32697801]

48. Sepucha KR, Abhyankar P, Hoffman AS, Bekker HL, LeBlanc A, Levin CA, et al. Standards for UNiversal reporting of patient Decision Aid Evaluation studies: the development of SUNDAE Checklist. BMJ Qual Saf 2018 May;27(5):380-388 [FREE Full text] [doi: 10.1136/bmjqs-2017-006986] [Medline: 29269567]

49. Hou S. Health literacy online: a guide to writing and designing easy-to-use health web sites. Health Promot Pract 2012 Sep;13(5):577-580. [doi: 10.1177/1524839912446480] [Medline: 22763891]

50. Health Literacy. National Institutes of Health (NIH). 2015. URL: https://www.nih.gov/institutes-nih/nih-office-director/ office-communications-public-liaison/clear-communication/health-literacy [accessed 2019-05-24]

51. Toolkit for Making Written Material Clear and Effective. Centers for Medicare Medicaid Services. 2012. URL: https:/ /www.cms.gov/Outreach-and-Education/Outreach/WrittenMaterialsToolkit/index.html [accessed 2019-05-24]

52. US Department of Health and Human Services. URL: https://www.hhs.gov/ [accessed 2019-08-07]

53. Woodard TL, Hoffman AS, Covarrubias LA, Holman D, Schover L, Bradford A, et al. The Pathways fertility preservation decision aid website for women with cancer: development and field testing. J Cancer Surviv 2018 Feb;12(1):101-114. [doi: 10.1007/s11764-017-0649-5] [Medline: 29034438]

54. Gonçalves V, Travado L, Ferreira PL, Quinn G. Protocol for the development and acceptability of a fertility-related decision aid for young women with breast cancer in Portugal. BMJ Open 2019 Jul 24;9(7):e030690 [FREE Full text] [doi: 10.1136/bmjopen-2019-030690] [Medline: 31345986]

55. Ehrbar V, Urech C, Rochlitz C, Dällenbach RZ, Moffat R, Stiller R, et al. Fertility preservation in young female cancer patients: development and pilot testing of an online decision aid. J Adolesc Young Adult Oncol 2018 Feb;7(1):30-36. [doi: 10.1089/jayao.2017.0047] [Medline: 28759303]

56. Benoit A, Grynberg M, Morello R, Sermondade N, Grandazzi G, Moutel G. Does a web-based decision aid improve informed choice for fertility preservation in women with breast cancer (DECISIF)? Study protocol for a randomised controlled trial. BMJ Open 2020 Feb 10;10(2):e031739 [FREE Full text] [doi: 10.1136/bmjopen-2019-031739] [Medline: $\underline{32047010]}$

57. Peate M, Meiser B, Friedlander M, Saunders C, Martinello R, Wakefield CE, et al. Development and pilot testing of a fertility decision aid for young women diagnosed with early breast cancer. Breast J 2011;17(1):112-114. [doi: 10.1111/j.1524-4741.2010.01033.x] [Medline: 21129095]

58. Benedict C, Ford JS, Schapira L, Simon P, Spiegel D, Diefenbach M. Family-building decision aid and planning tool for young adult women after cancer treatment: protocol for preliminary testing of a web-based decision support intervention in a single-arm pilot study. BMJ Open 2019 Dec 29;9(12):e033630 [FREE Full text] [doi: 10.1136/bmjopen-2019-033630] [Medline: 31888941] 
59. McCabe MS, Bhatia S, Oeffinger KC, Reaman GH, Tyne C, Wollins DS, et al. American Society of Clinical Oncology statement: achieving high-quality cancer survivorship care. J Clin Oncol 2013 Feb 10;31(5):631-640 [FREE Full text] [doi: 10.1200/JCO.2012.46.6854] [Medline: 23295805]

60. Smith AW, Seibel NL, Lewis DR, Albritton KH, Blair DF, Blanke CD, et al. Next steps for adolescent and young adult oncology workshop: an update on progress and recommendations for the future. Cancer 2016 Apr 1;122(7):988-999 [FREE Full text] [doi: 10.1002/cncr.29870] [Medline: 26849003]

\section{Abbreviations}

ASCO: American Society of Clinical Oncology

DA: decision aid

IPDAS: International Patient Decision Aid Society

IVF: in vitro fertilization

LGBTQ: lesbian, gay, bisexual, transgender, and queer/questioning

NCI: National Cancer Institute

NIH: National Institutes of Health

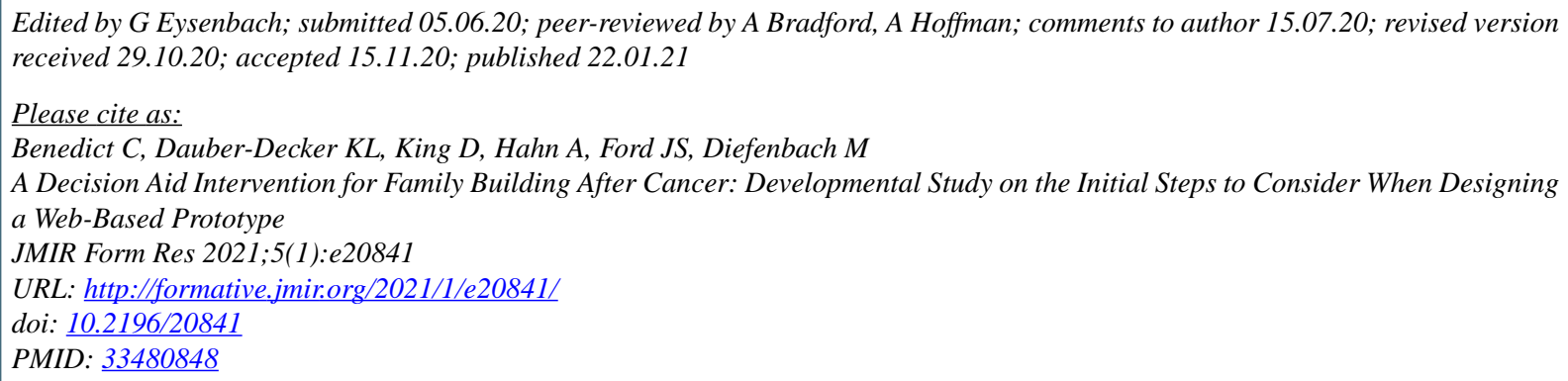

(C) Catherine Benedict, Katherine L Dauber-Decker, D'Arcy King, Alexandria Hahn, Jennifer S Ford, Michael Diefenbach. Originally published in JMIR Formative Research (http://formative.jmir.org), 22.01.2021. This is an open-access article distributed under the terms of the Creative Commons Attribution License (https://creativecommons.org/licenses/by/4.0/), which permits unrestricted use, distribution, and reproduction in any medium, provided the original work, first published in JMIR Formative Research, is properly cited. The complete bibliographic information, a link to the original publication on http://formative.jmir.org, as well as this copyright and license information must be included. 